\title{
Industry 4.0: The use of industrial automation with the internet assistance of the things in the control of electricity via local network in the city of Manaus-AM
}

\section{Charles Castro Ferreira ${ }^{1}$, José Roberto Lira P. Júnior ${ }^{2}$, Luiz Felipe de Araújo Costa ${ }^{3}$, Mauro Cesar Aparício de Souza ${ }^{4}$, David Barbosa de Alencar ${ }^{5}$, Antonio Estanislau Sanches ${ }^{6}$}

\author{
1,2 Universidade Nilton Lins UNINILTONLINS - Manaus-AM. \\ ${ }^{3,4}$ Centro Universitário FAMETRO - Manaus-AM. \\ ${ }^{5}$ Instituto de Tecnologia e Educação Galileo da Amazônia ITEGAM - Manaus-AM. \\ ${ }^{6}$ Universidade do Estado do Amazonas UEA - Manaus-AM.
}

Email: charles_castro_ferreira@yahoo.com.br, robertojunior72@gmail.com, luizfelipe_am@hotmail.com, mcas1691@gmail.com, david002870@hotmail.com, novo.sanches@gmail.com

\author{
Received: January $11^{\text {th }}, 2019$ \\ Accepted: January $20^{\text {th }}, 2019$ \\ Published: March $31^{\text {th }}, 2019$ \\ Copyright (C2016 by authors and \\ Institute of Technology Galileo of \\ Amazon (ITEGAM). \\ This work is licensed under the \\ Creative Commons Attribution \\ International \\ License (CC BY 4.0). \\ http://creativecommons.org/licenses/by/4.0/
}

\section{ABSTRACT}

In Brazil the residential automation is still a field of operation little explored. This work proposes the use of a prototype, which through the internet concept of things, can help control and reduce the consumption of residential electricity. The development of the methodology of this research was done through the collection of data and through a bibliographic review, from which it was possible to study the possible superiorities existing in a higher level of detail about the relationship between Home Automation Technology and the Internet of Things. The creation of a low cost prototype for a control of electrical energy of a residence through local network, through the platform Arduino Mega 2560, whose microcontrollers is ATmega 2560, connected to the ethernet shield plate in order to establish connection with the local network to receive request from the user and send the command via RF to the drive module perform the command, proved to be effective in controlling and reducing residential power. It was possible to monitor the cost and energy consumption in a practical and instant way, making the best possible use of available resources and components.

Keywords: Domotics Technology; Internet of Things; Electricity; Reduction; Industry 4.0.

\section{Indústria 4.0: $O$ uso da automação industrial com o auxílio da internet das coisas no controle de energia elétrica via rede local na cidade de Manaus-AM}

RESUMO

No Brasil a automação residencial ainda é um campo de atuação pouco explorado. Este trabalho propõe a utilização de protótipo, que através do conceito internet das coisas, possa auxiliar no controle e redução do consumo de energia elétrica residencial. O desenvolvimento da metodologia dessa pesquisa foi realizado através da coleta de dados e por meio de uma revisão bibliográfica, da qual foi possível estudar as possíveis superioridades existentes em maior nível de detalhamento acerca da relação entre Tecnologia Domótica e a Internet das Coisas. A criação de um protótipo de baixo custo para um controle de energia elétrica de uma residência através de rede local, através da plataforma Arduíno Mega 2560, cujo microcontroladores é ATmega 2560, conectada a placa ethernet shield a fim de estabelecer conexão com a rede local para receber requisição do usuário e enviar o comando por meio de RF para o módulo de acionamento executar o comando, mostrou-se eficaz no controle e redução da energia elétrica residencial. Foi possível monitorar o custo e consumo de energia de forma prática e instantânea, fazendo o melhor uso possível dos recursos e componentes disponíveis.

Palavras-Chave: Produtividade; Eficiência; Redução de custos; Logística; 


\section{INTRODUÇÃO}

A Internet das Coisas está a cada dia mais inserida na nossa sociedade, com o passar das últimas décadas, mais processos estão integrados através de sistemas automatizados e eletrônicos. É uma integração que ocorre até na vida social, do lado de fora da indústria, equipamentos eletrônicos que se comunicam com seus proprietários e sinalizam suas necessidades, como é o exemplo das geladeiras inteligentes, que são capazes de fazer compras dos itens em falta em seu interior e debitar o valor diretamente do proprietário, que receberá os itens via delivery ou poderá retirá-los no supermercado. Os avanços tecnológicos proporcionam mais produtividade à indústria e aumentam sua competitividade em níveis globais, entretanto, quanto mais automação a consequência direta é a redução de mão de obra humana. Nesse contexto, levanta-se a questão a ser respondida nesse estudo: Como a relação entre a tecnologia domótica e as ferramentas da internet das coisas, podem auxiliar no controle e redução da enérgica elétrica residencial?

O objetivo deste trabalho é propor a utilização de protótipo, que através do conceito internet das coisas, possa auxiliar no controle e redução do consumo de energia elétrica residencial. Para tal, propôs-se a descrever o conceito de Internet das Coisas assim como sua evolução e utilização na Indústria 4.0; Contextualizar acerca do Sistema de Domótica aplicada ao controle de Energia Elétrica; e, Pontuar a utilização da IoT no processo de Automação Residencial, para tentar reduzir o custo da energia elétrica em até $30 \%$.

\section{REFERENCIAL TEÓRICO}

\section{II.1 O QUE É INTERNET DAS COISAS?}

A Internet das Coisas pode ser um tema quente na indústria, mas não é um conceito novo. No início dos anos 2000, Kevin Ashton estava lançando as bases para o que se tornaria a Internet das Coisas (IoT) no MIT AutoID lab. Ashton foi um dos pioneiros que concebeu esta noção ao procurar maneiras que Proctor \& Gamble poderia melhorar seu negócio, ligando informações RFID para a Internet [1]. O conceito era simples, mas poderoso. Se todos os objetos na vida diária fossem equipados com identificadores e conectividade sem fio, esses objetos podem ser comunicados entre si e gerenciados por computadores. Ashton escreveu: Se tivéssemos computadores que soubessem tudo o que havia para saber sobre as coisas - usando dados que eles reuniram sem qualquer ajuda de nós - seríamos capazes de controlar e contar tudo, e reduzir significativamente o desperdício, perda e custo [1].

Hoje, muitos desses obstáculos foram resolvidos, haverá bilhões de objetos conectando-se à rede com os próximos anos. Por exemplo, o Cisco's Internet of Things Group (IOTG) prevê que haverá mais de 50 bilhões de dispositivos conectados em 2020 [2].

Em nações que lideram esse movimento, como Estados Unidos e Alemanha, indústrias de ponta estão investindo cada vez mais em Smart Factories ou fábricas inteligentes [3].

Com o uso de sensores e softwares sofisticados, as máquinas, que antes apenas respondiam a comandos externos, agora são capazes de reunir milhões de informações, processálas e interagir com outras máquinas - e até com outras fábricas.

Tudo, quase sem intervenção humana, por meio da internet. "É uma nova manufatura que está surgindo", diz Helmuth Ludwig, vice-presidente executivo da subsidiária norte-americana da alemã Siemens, uma das empresas que está à frente dessa tendência. A nova indústria promete não apenas ser mais eficiente, mas revolucionar o relacionamento com o mercado [4].

No futuro, diz Ludwig, as fábricas terão a capacidade de alterar sua configuração de forma rápida, modificando as características dos produtos para atender demandas específicas de clientes e consumidores. É o que vem sendo chamado de customização em massa [5].

\section{II.1.1 COMO FUNCIONA IOT}

IoT descreve um sistema onde itens no mundo físico e sensores dentro ou anexado a esses itens, estão conectados à Internet através de conexões sem fio e com fio à Internet. Esses sensores podem ser tipos de conexões locais, como RFID, NFC, Wi-Fi, Bluetooth e Zigbee. Os sensores também podem ter conectividade de área ampla, como GSM, GPRS, 3G, 4G e LTE [4].

A Internet das Coisas conecta tanto seres vivos como inanimados. Primeiras experiências e implantações da internet das coisas nas redes começaram com a conexão de equipamentos industriais. Hoje, a visão da IoT se expandiu para conectar tudo, desde equipamentos industriais aos objetos do dia-a-dia. Os tipos de itens variam de turbinas a gás a automóveis para medidores de utilidade. Também pode incluir organismos vivos, como plantas, animais e pessoas. Por exemplo, o Cow Tracking Project em Essex usa dados coletados de rádio posicionamento de tags para monitorar vacas para a doença e controlar o comportamento no rebanho. Computações vestíveis e Dispositivos digitais de saúde, como a Nike + Fuel band e Fitbit, são exemplos de como as pessoas estão se conectando a Internet das coisas a paisagem. A Cisco expandiu a definição de IoT para a Internet de Tudo (IoE), que inclui pessoas, lugares, objetos e coisas. Basicamente qualquer coisa que você pode anexar um Sensor e conectividade pode participar nos novos ecossistemas conectados [6].

Usa sensores para a coleta de dados. Os objetos físicos que estão sendo conectados possuem um ou mais sensores. Cada sensor monitorará uma condição específica, como localização, vibração, temperatura. No IoT, esses sensores se conectarão entre si e com sistemas que possam entender ou apresentar as informações dos feeds de dados do sensor. Estes sensores fornecerão novas informações aos sistemas da empresa e às pessoas [6].

Altera os tipos de itens que se comunicam através de uma rede IP. No passado, seria pessoas com pessoas, e pessoas com máquinas. Imagine se todos os seus equipamentos tivessem a capacidade de se comunicar. O que você diria? Os objetos habilitados para IoT compartilharão informações sobre sua condição e os ambientes com pessoas, sistemas de software e outras máquinas. Essas informações podem ser compartilhadas em tempo real ou coletados e compartilhados em intervalos definidos. No futuro, tudo terá uma identidade digital e conectividade, o que significa que você pode 
identificar controlar e comunicar com objetos. Os dados IoT diferem da computação tradicional. Os dados podem ser de pequeno tamanho e frequente na transmissão. O número de dispositivos, ou nós, que estão se conectando a rede também são maiores em IoT do que em computador tradicional.

Comunicações e inteligência máquina a máquina extraídas dos dispositivos e a rede permitirá que as empresas automatizem certas tarefas básicas sem depender da central ou serviços baseados em nuvem. Esses atributos apresentam oportunidades para coletar uma ampla gama de dados, mas também proporcionar desafios em termos de concepção de rede de dados adequada e segurança desses dados [6].

A Internet das Coisas também é uma realidade já presente na vida do consumidor final, e será cada vez mais inserida ao longo da próxima década, não ficando apenas restrita ao conceito de total automação da indústria, sendo também um grande "facilitador" da vida doméstica [3].

Uma das primeiras coisas inseridas na vida doméstica, tendo por volta de um Milhão de casas conectadas no Brasil a cerca de 10 anos, é a porta. Proporcionando maior segurança residencial com painéis de alarme instalados na porta que está programada para abrir apenas para moradores do local reconhecendo rostos e/ou digitais, e essa ideia foi passando para janelas, sensores de presença, sensores de movimento. E tudo isso é monitorado virtualmente pelos moradores e até por empresas que prestam serviços de segurança patrimonial [2].

A área de segurança é um dos principais nichos fora da Indústria para a Internet das Coisas, logo na sequência vem à conexão de veículos que estão conectados coletando informação de localização, condução, desempenho, que são enviadas para centrais para diversos tipos de aplicação, inclusive para segurança do condutor em uma possível situação de violência ou furto. Num campo mais simplificado, também temos aparelhos domésticos que se conectam a rede para melhorar a experiência dos usuários, como televisores e geladeiras [4].

Dispositivos como pulseiras para atividades físicas que monitoram a frequência cardíaca, nível de intensidade do exercício, gasto calórico e armazenam essas informações em aplicativos que analisam essas informações e transformam esses dados em programas de evolução [5].

\section{II.2 IMPLANTAÇÃO DA IoT}

A implantação da IoT irá gerar uma grande quantidade de dados, além de serem informações que podem comprometer a privacidade dos usuários, o perfil da rede deverá suportar o intenso tráfego de dados sem permitir que haja interrupções, quedas e quebra de sigilo. Apesar de já termos alguns recursos em funcionamento, ainda existem alguns desafios a serem vencidos para que seja implantada de forma total. Entre esses desafios, os mais críticos são as questões de segurança, privacidade, gestão e armazenamento destes dados [2].

\section{II.3 ESTRATÉGIAS NO PAÍS}

O Brasil está atrasado nesse terreno, embora abrigue empresas que usam tecnologia de ponta e tenham grau de excelência nos setores em que atuam. Nessa linha de raciocínio [2] relata, que de maneira geral, porém, o país investe pouco em inovação e tem um ambiente regulatório considerado inadequado. Além disso, não tem uma rede confiável de internet em banda larga e forma poucos engenheiros e técnicos especializados, essenciais para o desenvolvimento da nova indústria.

Em março de 2016, o governo criou um grupo de trabalho interministerial com a tarefa de mapear a capacidade existente no Brasil nessa área, identificar gargalos e formular uma estratégia para inserir o país na rota do novo avanço tecnológico. A diretora de Desenvolvimento Tecnológico e Inovação da Agência Brasileira de Desenvolvimento Industrial (ABDI), Maria Luísa Machado Leal, reconhecem as deficiências, mas diz que é possível recuperar terreno.

Para Maria Luísa, o país pode saltar etapas se houver articulação entre governo, setor privado e universidades, e se forem estabelecidas parcerias internacionais para absorver conhecimentos já desenvolvidos lá fora. Um dos problemas mais difíceis é que a atualização tecnológica requer investimentos, que estão em queda no país.

$\mathrm{Na}$ avaliação dela, será preciso criar mecanismos de financiamento para apoiar a atualização do parque industrial. "A crise atual impede as empresas de definir grandes investimentos, mas temos que nos preparar para isso. Em pouco tempo, nossos principais concorrentes vão operar nesse novo ambiente tecnológico", diz a diretora da ABDI [7].

\section{II.4 TECNOLOGIA DOMÓTICA}

Com relação ao segundo objetivo desse estudo, que busca contextualizar acerca do Sistema de Domótica aplicada ao controle de Energia Elétrica, salienta-se que a Tecnologia Domótica é uma tecnologia recente que permite a gestão de todos os recursos habitacionais. O termo "Domótica" resulta da junção da palavra latina "Domus" (casa) com "Robótica" (controle automatizado) [8].

Nesse sentido, pode-se destacar que a Robótica está ligada ao ato de automatizar, isto é, realizar ações de forma automática. A domótica tem uma grande importância para a acessibilidade, uma vez que facilita a interação de pessoas que tenham algum tipo de deficiência física com os mecanismos do dia-a-dia, de forma que se ajuste às suas necessidades e se mostrado cada vez mais presente em nossas vidas.

Isso pode ser evidenciado quando se observa um trecho dos estudos de [9] onde o autor aponta algumas utilizações da automação feita através da robótica, conforme se elenca a seguir:

Indústrias - Automação Industrial responsável pelo controle das máquinas produtivas em operação;

Comércio - Automação Comercial responsável pelo controle e gerenciamento dos estoques e nas finanças e provendo agilidade nas operações comerciais através de códigos de barras, magnéticos ou por ondas de rádio.

Predial - Automação Predial responsável pelo controle das tarefas comuns aos condôminos de um edifício residencial ou comercial trata de assuntos tais como: elevadores, iluminação, área de lazer e trabalho cooperado, entre outros.

Doméstica - Automação Residencial responsável pelo controle e gerenciamento dos afazeres domésticos, provendo maior segurança e comodidade no lar. 
Visto isto, pode-se dizer que a automação residencial, mais cedo ou mais tarde, tornar-se-á comum para a sociedade e traz consigo mudanças incontestáveis nos projetos e construções habitacionais, fazendo com que proporcione mais conforto, comodidade e satisfação ao público alvo. "O termo Automação Residencial designa e referência à utilização de processos automatizados em casas, apartamentos e escritórios. Podem-se utilizar outras denominações sinônimas, tais como, Automação Doméstica, Automatização Residencial ou Domótica. Apesar dos conceitos de Automação Residencial, ou ainda Ambientes Inteligentes, apresentarem-se como futuristas, o potencial é enorme" [9].

\section{MATERIAIS E MÉTODOS}

Este trabalho foi realizado através do uso de técnicas como a observação, que aproxima o pesquisador da realidade pesquisada, e a entrevista informal que possibilitou o aprofundamento das informações conseguidas que complementa os dados obtidos.

\section{III.2 APRESENTAÇÃO DOS DADOS COLETADOS}

O sistema funciona da seguinte forma: os sensores de corrente colhem os dados das cargas dos equipamentos ligados às tomadas residenciais e estes dados são enviados para 0 Arduino onde serão processados, transformados em informações e serão exibidas no computador.

Inicialmente foram adquiridos todos os componentes eletrônicos necessários para a concepção do modelo.

Para o cálculo da potência consumida e obtenção dos custos com energia foi utilizado um sensor de corrente ASC712. As medições de corrente foram realizadas de forma precisa com o Sensor de Corrente ACS712. Este sensor usa o efeito hall para detectar o campo magnético gerado pela passagem de corrente, gerando na saída do módulo (pino OUT), uma tensão proporcional de $66 \mathrm{mV} / \mathrm{A}$. O sensor de corrente ACS712 mostrado na Figura 3 pode ser utilizado com corrente alternada (AC) e corrente contínua (DC), e os bornes de ligação são completamente isolados da saída para o microcontrolador.

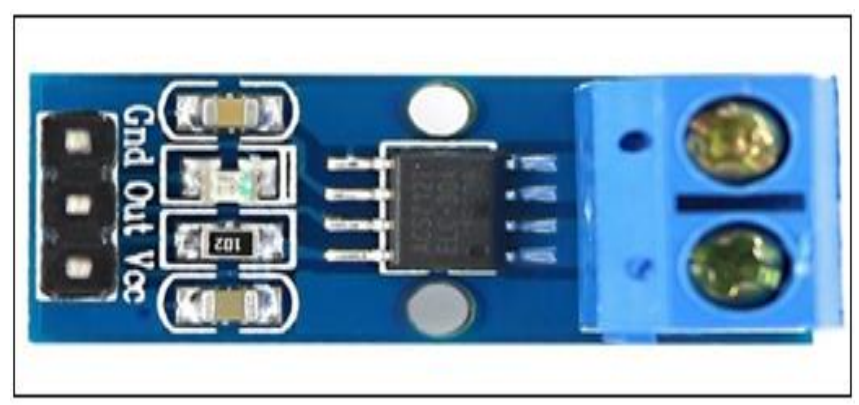

Figura 1: Sensor de Corrente ASC712. Fonte: Autores, (2018).

\section{III.3 ANÁLISES DOS RESULTADOS}

Este capítulo visa comunicar os resultados obtidos pelo autor da pesquisa e análise dos mesmos, bem como oferecer subsídios para a conclusão do estudo. Onde foram feitas a análise dos dados, sua interpretação e discussões que foram conjugadas através de texto e apresentados os métodos separadamente. Os resultados foram agrupados e ordenados de maneira conveniente através de tabelas, gráficos e figuras, em resposta aos objetivos desse estudo. A concretização deste capítulo vem possibilitar a ligação entre novas descobertas e os conhecimentos apresentados na revisão da bibliográfica.

\section{III.3.1 VERIFICAÇÃO DA TENSÃO}

Tensão (ou diferença de potencial) é a energia necessária para mover uma unidade de carga através de um elemento, é medida em volts (V) [10]. Pode ser definida pela razão entre a quantidade de energia W medida em Joules (J) e a carga Q, conforme é mostrado na equação 1:

$$
\mathrm{V}=\frac{\mathrm{W}}{\mathrm{Q}}
$$

Sendo:

$\mathrm{V}=$ Tensão (Volts);

$\mathrm{W}=$ Energia $(\mathrm{W})$;

$\mathrm{Q}=\operatorname{Carga}(\mathrm{C})$;

A corrente elétrica é por definição a taxa de fluxo de cargas elétricas através de uma superfície [11] - geralmente essa superfície é a seção transversal de um fio condutor. Sendo $\Delta \mathrm{Q}$ (medida em Coulomb) a carga que flui através da área da seção transversal do fio no tempo $\Delta \mathrm{t}$, a intensidade da corrente I medida em ampères. A equação 2 mostra como podemos calcular a intensidade dessa corrente:

$$
I=\underline{\Delta Q}
$$

Sendo:

$\mathrm{I}=$ Corrente $(\mathrm{A})$;

$\Delta \mathrm{Q}=$ Variação de carga $(\mathrm{C})$;

$\Delta \mathrm{t}=$ Tempo em segundos $(\mathrm{s})$;

A Amazonas Energia nos fornece uma tensão de $127 \mathrm{~V}$ ou $220 \mathrm{~V}$, no entanto com a estrutura e recursos disponíveis atualmente, é impossível para a Amazonas Energia fornecer para cada residência uma tensão exata e sem variações. Portanto a ANEEL com o respaldo da PORTARIA DNAEE N $^{\circ}$ 047, DE 17 DE ABRIL DE 1978 permite que se tenha um limite de variação de tensão nominal de $5 \%$ para mais ou para menos para cada cliente [12]. Para a programação desenvolvida neste trabalho, o ideal seria se a tensão fosse fixa e sem variações, pois os cálculos do consumo são realizados de acordo com um valor de tensão previamente determinado.

Como isso não é possível, a tensão real fornecida para a residência utilizada foi medida ao longo de um dia e o valor da moda dos dados foi utilizado no código-fonte [12].

\section{III.3.2 TESTE DE ENERGIA NA LÂMPADA DE 40W}

Energia é a capacidade de realizar trabalho. É medida em joules (J) ou ainda em watt-segundo e Potência é a variação da energia (liberada ou absorvida) em função da variação do tempo, medida em watts (W) [10]. Sendo assim a Energia 
consumida ou fornecida será definida conforme mostrado na equação 3:

$$
\mathrm{W}=\mathrm{Pt}
$$

Sendo:

$\mathrm{W}=$ Energia (watt);

$\mathrm{P}=$ Potência (watt por segundo ou $\mathrm{j} / \mathrm{s}$ );

$\mathrm{t}=$ Tempo em segundos (s);

A potência será encontrada pela equação 4:

$$
\mathrm{P}=\mathrm{VI}
$$

Sendo:

$\mathrm{P}=$ Potencia (watt por segundo ou $\mathrm{j} / \mathrm{s}$ );

$\mathrm{V}=$ Tensão (Volts);

$\mathrm{I}=$ Corrente $(\mathrm{A})$;

A princípio, o tempo utilizado nos cálculos de potência será expresso em segundos. No entanto para fins práticos, serão utilizados o Wh (watt-hora) e o kWh (quilowatt-hora). Portanto a energia consumida será dada por:

Energia $(W h)=\operatorname{potência~}(W) \times$ tempo(h) $-($ Equação 1$)$

Ou por:

Energia $(\mathrm{kWh})=$ potência $(\mathrm{W}) \times$ tempo $(\mathrm{t})-($ Equação 2$)$ 1000

Para realizar o teste no sensor de corrente, foi montado um circuito e um código de programação com apenas esse sensor conectado ao Arduino (Figuras 3-5). A plataforma Arduino inclui ainda um meio de desenvolvimento que permite escrever programas usando uma linguagem denominada Processing, que é uma linguagem derivada de um projeto de alunos do MT (Instituto de Tecnologia de Massachusetts EUA), que tem como grande objetivo facilitar o acesso de programadores ao mundo da programação de baixo nível (exemplo de linguagem: Assembly), sem necessidade alguma de conhecer a linguagem de máquina, que trabalha diretamente com os registradores dos processadores. A linguagem de programação de alto nível adotada pelo projeto Processing é uma versão simplificada da linguagem $\mathrm{C} / \mathrm{C}++$.

De acordo com o Manual CCS Inc. (2007) Processing é uma linguagem de programação de código aberto para as pessoas que querem criar imagens, animações e interações.

Desenvolvido inicialmente para servir como um "Sketchbook" do software e para ensinar os fundamentos da programação de computador dentro de um contexto visual, Processing igualmente evoluiu em uma ferramenta para gerar trabalho profissional de qualidade em sua forma final. Atualmente, existem dezenas de milhares de estudantes, artistas, designers, pesquisadores e entusiastas que utilizam a linguagem Processing para a aprendizagem, a prototipificação e a produção.

Para desenvolver aplicações utilizando a linguagem Processing, que funcionem em um microcontrolador, é utilizado um conjunto de abstrações, de codinome Wirin. Muitos se referem a este conjunto como linguagem Wiring ou linguagem Arduíno, mas na verdade são somente funções e bibliotecas escritas em C/C++ (CCS Inc., 2007). A Figura 2 mostra o ambiente do desenvolvimento para o Arduino.

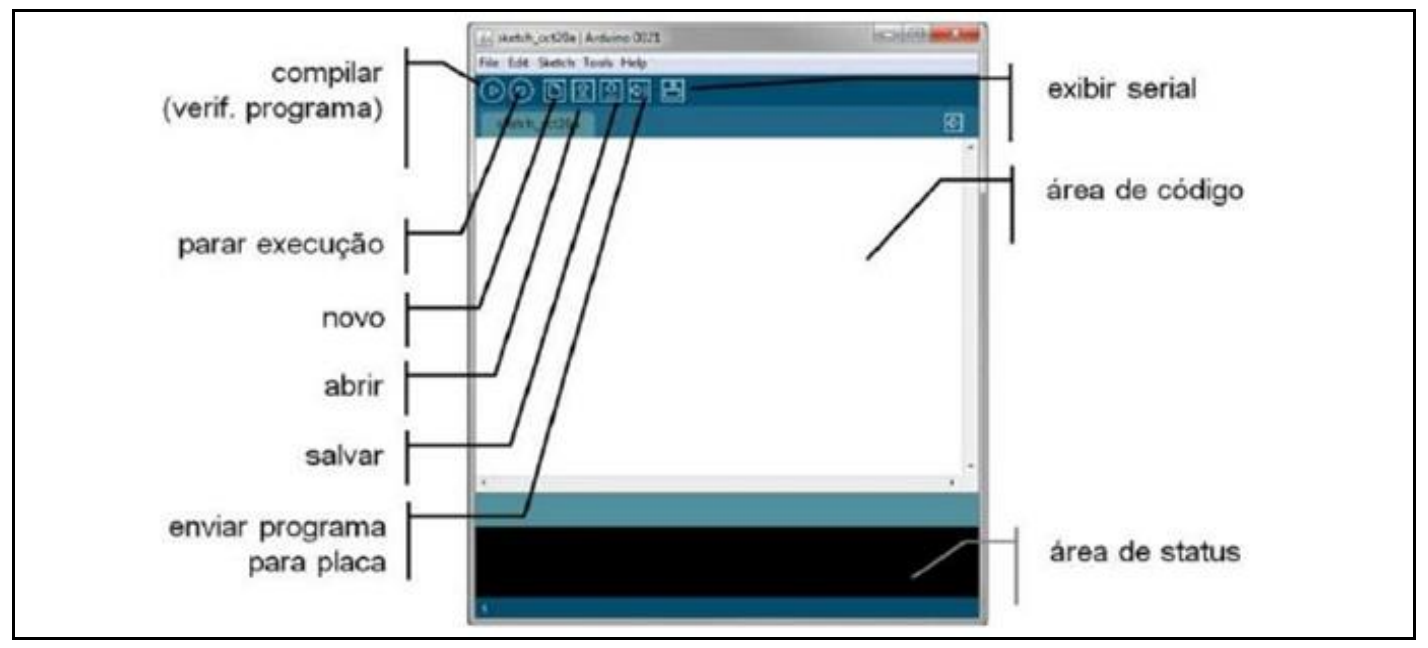

Figura 2: Ambiente de desenvolvimento Arduino.

Fonte: Autores, (2018).

O código-fonte utilizado foi o do fabricante, porém com as alterações da faixa de tensão. Efetuou-se então a medição de potência e corrente consumidas por uma lâmpada de 40W. A corrente também foi medida através de um multímetro simultaneamente. Para realizar o teste no sensor de corrente, foi montado um circuito e um código de programação com apenas esse sensor conectado ao Arduino.

\section{III.3.3 TESTE CHURRASQUEIRA ELÉTRICA}

Os testes iniciaram-se com a medição de potência e corrente em uma churrasqueira elétrica de 1800W. De acordo com [13] apesar das oscilações, o sensor se aproximou bastante da medição de corrente realizada pelo multímetro, no entanto a potência medida ficou abaixo dos $1800 \mathrm{~W}$ descritos na embalagem do aparelho. É importante salientar que os aparelhos domésticos, principalmente os que têm finalidade de 
resistência térmica, geralmente não consomem a potência exata de acordo com sua descrição por várias causas. Na Tabela 1 podemos observar o teste da corrente elétrica, numa churrasqueira elétrica.

Tabela 1: Teste Sensor de Corrente /

\section{Churrasqueira.}

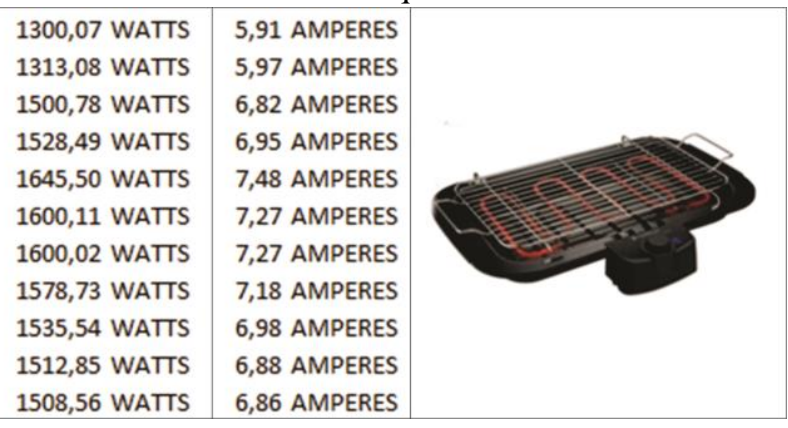

Fonte: Autores, (2018).

Entre estas causas podem estar variações na fabricação e arredondamento de valor de potência para fins comerciais. Isso foi comprovado na medição da churrasqueira elétrica, pois a corrente e a tensão se mantiveram estáveis no momento da medição da potência [13].

\section{III.3.4 MONTAGEM DO PAINEL}

Seguimos para a montagem do projeto de forma na quais todos os componentes foram fixados de forma adequada no compartimento, a Figura 3 mostra a evolução do projeto.

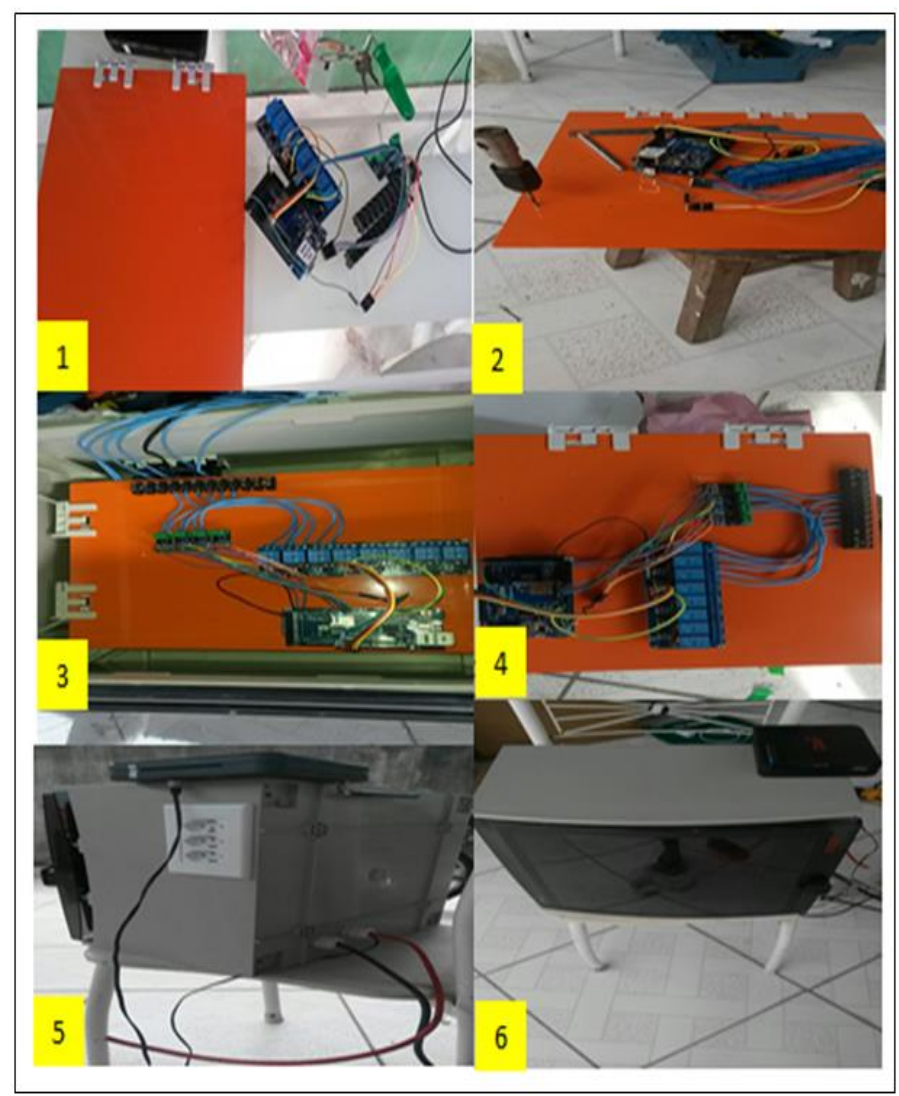

Figura 3: Painel do Projeto.

Fonte: Autores, (2018).
Uma vez realizados os testes necessários, foi observado que o sensor não possui uma precisão extremamente exata, mas que atende aos propósitos deste trabalho. A Figura 4 mostra o consumo da energia num ambiente virtual.

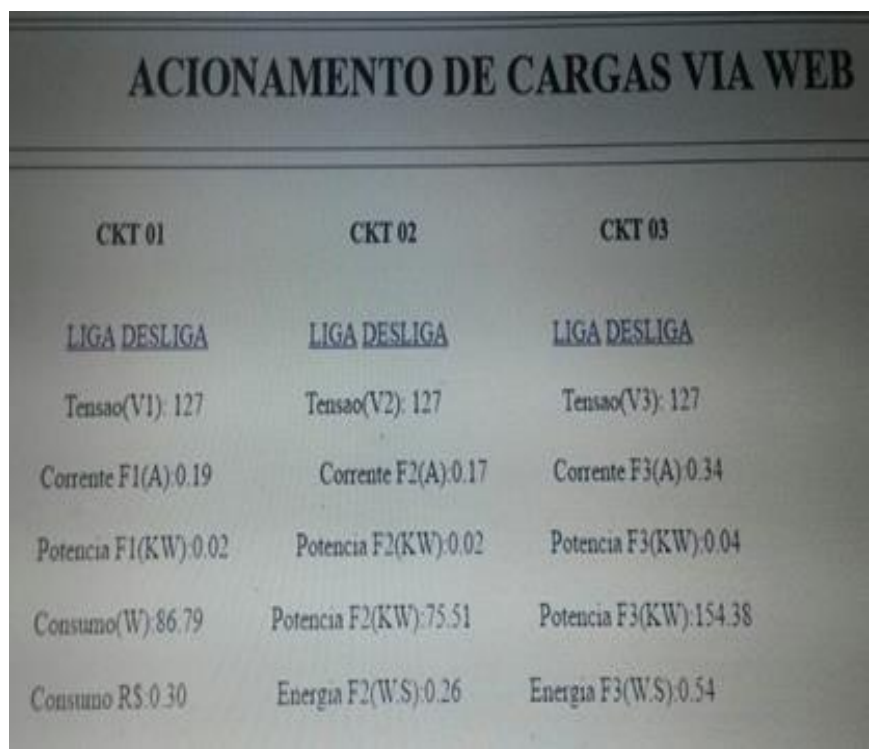

Figura 4: Amostra de consumo via WEB. Fonte: Autores, (2018).

\section{CONSIDERAÇÕES FINAIS}

A IoT vai mudar nossa realidade, por que agora tudo é inteligente, e está conectado, de modo que possamos ter acesso a tais dados, ou melhor, à informação, A IoT vai revolucionar a vida dos seres humanos, a partir do momento que os mesmos compreenderem que com uso dessa tecnologia, se pode melhorar a vida das pessoas e organizações. A Internet das Coisas irá transformar fundamentalmente como os produtos são inventados, fabricados, enviados e vendidos. Os principais fabricantes estão projetando produtos e serviços em constante evolução, isso é um fator determinante para mudar o direcionamento das coisas como conhecemos atualmente. Uma das áreas com mais alto potencial para aplicações da IoT, é a da saúde, utilizando aplicações para dispositivos móveis, assim podendo acompanhar diagnósticos dos pacientes em tempo real num aparelho celular, porém um dos desafios dessa aplicação está em proteger tais informações, para que apenas os prestadores de serviços de saúde tenham acesso a tais informações, apesar disso é animador a evolução que acontece nessa área, algo para se acompanhar de perto. Com a automação industrial, o mundo passou a produzir de forma mais eficiente e com menor custo, constantemente as empresas pensam em automatizar processos produtivos pensando em ter um retorno financeiro a médio e longo prazo. Com a IoT, a automação fica mais viável não só nas organizações, como também nas residências. No futuro tudo será mais dinâmico, automático e intuitivo. A automação industrial já é uma realidade no presente, contribuindo para a evolução da indústria, aumentando a escala de produção e reduzindo custos ao mesmo tempo, já a automação residencial será algo mais explorado pelas futuras gerações, pois através dela será possível criar métodos que facilitem o dia-a-dia das pessoas deixando tudo mais "automático". 


\section{REFERÊNCIAS BIBLIOGRÁFICAS}

[1] ASHTON, Kevin. An Introduction to the Internet of Things (IoT). RFID Journal. 1999.

[2] Zambarda, Pedro. Internet das Coisas: entenda o conceito e o que muda com a tecnologia, 2018. Disponível em: <http://www.techtudo.com.br>. Acessado em: 14. abr. 2018.

[3] Ashton, Kevin. Internet das Coisas, nova revolução da conectividade. Porto Alegre: 2014. Inovação em Pauta, Porto Alegre, n. 18, p. 6-9, 14 dez. 2014.

[4] Figueiredo, Odail. Setor automobilístico está a caminho da indústria 4.0. 2016. Disponível em: 〈http://www.em.com.br〉. Acessado em: 04. mai.2018.

[5] Hamann, Renan. 5 tendências tecnológicas para os próximos anos, 2014.2 Disponível em <http://www.tecmundo.com.br>. Acessado em: 22. abr.2018.

[6] Evans, Dave. Internet das Coisas: Como a Próxima Evolução da Internet Está Mudando Tudo, 2011. Disponível em: 〈http://www.cisco.com>. Acessado em: 04. mai.2018.

[7] Agencia Brasileira do Desenvolvimento Industrial (ABDI), 2018. Disponível em: <http://www.abdi.com.br>. Acessado em: 15. Mai. 2018.

[8] Chaves, Bel. O que é domótica, 2015. Disponível em: <http://www.belchaves.com.br>. Acessado em: 28. abr.2018.

[9] Teza, Vanderlei Rabelo. Alguns aspectos sobre automação residencial - DOMÓTICA. [Monografia]. Florianópolis: UFSC, 2002.

[10] Alexander, Charles; Sadiku, Matthew N. O. Fundamentos de Circuitos Elétricos. 5. ed. São Paulo: Bookman, 2013.

[11] Tipler, Paul A.; Mosca, Gene. Física Para Cientistas e Engenheiros. 6. ed. Rio de Janeiro: Ltc, 2009.

[12]. Agência Nacional de Energia Elétrica (ANEEL) - Banco de Informações de Geração: Big, 2018. Disponível em: <http://www.aneel.gov.br>. Acessado em: 11. Mai.2018.

[13] Loes, João; Steinhauser, Rafael. O que é a internet das coisas e como ela mudará suas vidas, 2015. Disponível em: <http://tecnologia.terra.com.br >. Acessado em: 3. Mai.2018. 